\title{
Therapy and aesthetics achieved by a toxin- Botulinum: A comprehensive review
}

\author{
Yogeshwari Krishnan ${ }^{1, *}$, Akram Belmehdi ${ }^{2}$, Lakshya Vishnoi ${ }^{3}$, Jyotsna Seth ${ }^{4}$ \\ ${ }^{1}$ Intern, ${ }^{2}$ Consultant Oral Surgeon, Faculty of Rabat, Mohamed V University, Kingdom of Morocco, ${ }^{3}$ BDS Student, ${ }^{4}$ Reader, \\ Seema Dental College and Hospital, Rishikesh, Uttrakhand, India
}

*Corresponding Author:

Email: dryogeshwari1@gmail.com

\begin{abstract}
Botox is a drug derived from clostridium botulinum which is the same bacteria from which food poisoning is caused. It had been accepted long back for the treatment of lines and wrinkles. The only FDA approved uses of Botox were for abnormal muscle spasms of the eyelids (blepharospasm) and crossed eyes (strabismus). Since then this botulinum A and seven other forms of the botulinum toxin, have been continuously tested and researched on the toxin inhibits the release of acetylcholine (ACH) which is a neurotransmitter responsible for the activation of muscle contractions and glandular secretions, and its administration results in the reduction of tone in the injected muscles. The use of Botox is a procedure which is minimally invasive and is showing quite promising results in the management of muscle-generated dental diseases like Temporomandibular disorders, bruxism, clenching, masseter hypertrophy etc. Also being used to treat functional or esthetic dental conditions like deep nasolabial folds, radial lip lines, high lip line and black triangles between teeth and a lot more.
\end{abstract}

Keywords: Botulinum Toxin, Therapeutic Uses, Aesthetic Uses, Botox , Dermal Fillers.

\section{Introduction}

We all thrive to look young! Whenever we hear about botox the first thing that strikes our mind is its cosmetic use. Botox is an option which claims to give a younger and hence more esthetic look to people of advancing ages. There is no doubt that BOTOX and dermal fillers are well known for their esthetic results. like that of smoothening of the skin and replacing the lost volume of the face, especially in the oral and the perioral areas. ${ }^{1}$ Introduced in 1989 by Allergan Inc (www. allergan.com), Irvine, calif . ${ }^{2}$

\section{History}

German physician Justinus Kerner (1786-1862) first developed the idea for a possible therapeutic use for botulinum toxin. ${ }^{3}$ He deduced that the toxin acted by interrupting the signal transmission within the peripheral sympathetic nervous system, leaving sensory transmission intact. He called the toxin a "sausage poison," because the illness followed ingestion of spoiled sausage. In 1870, John Muller, another German physician, coined the term "botulism" (from the Latin root botulus, which means "sausage". In 1897, Emile van Ermengem discovered that the producer of the botulin toxin was a bacterium, which he named clostridium botulinum. In 1928, P.Tessmer Snipe and Hermann Sommer purified the toxin for the first time. ${ }^{4}$

In 1949, Arnold Burgen's group discovered that botulinum toxin blocks neuromuscular transmission through decreased acetylcholine release. Scott et al. proved this fact by administering the Type A strain into monkeys. Serotype B has been FDA approved for treating cervical dystonia, and serotype $\mathrm{F}$ is under investigation for patients who are resistant to serotypes $\mathrm{A}$ and $\mathrm{B} .^{5}$
The Food and Drug Administration (FDA) first approved Botox in 1989 and, its FDA approved uses have expanded to various medical conditions including cervical dystonia,urinary incontinence, chronic migraines, and certain types of eye muscle problems ${ }^{6}$ In 2002 , the FDA approved botulinum toxin type A for purely cosmetic use to improve the look of moderate to severe frown lines between the eyebrows (i.e the glabellar lines), and in 2013 it was approved for temporary improvement of "crow's feet" in adults. Botox has been proved itself to be a very effective, nonsurgical tool in cosmetic treatment. Since the effects of Botox last for only about four to six months, claims of serious permanent injuries are seldom. ${ }^{7}$

\section{Preparation}

Botox is prepared by the lab fermentation of Clostridium botulinum, which lyses and liberates the toxin into the culture. The toxin is then harvested, purified, crystallized with ammonium sulfate and diluted with human serum albumin, lyophilized. Then it is bottled in vials, and sealed. ${ }^{5}$

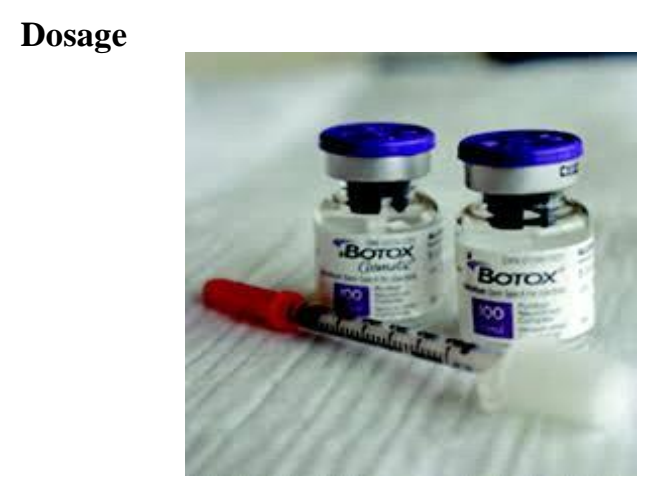


The human lethal dose is estimated to be approximately 3,000 U. Each vial contains $100 \mathrm{U}$ of Botox. Botox dosage used for cosmetic purposes typically are less than $100 \mathrm{U}$. Optimal $\mathrm{pH}$ of the solution ranges from 4.2 to 6.8 . The vials should be stored at or below $-5^{\circ} \mathrm{C}$.

Preparations should be reconstituted with 1-5 ml of saline without preservatives just before use. As Botox is easily denatured via bubbling or agitation, the diluents should be gently injected into the inside wall of the vial. The reconstituted solution should be refrigerated at 2$8^{\circ} \mathrm{C}$ and used before 4 hours. ${ }^{8}$

\section{Mechanism of Action}

The botulinum toxin causes paralysis of the muscles by inhibiting acetylcholine release at the neuromuscular junction through these 3 steps as shown in the Flow chart Below: ${ }^{9}$

Toxin binds to the nerve

$$
\downarrow
$$

Toxin is then cleaved by internal proteolytic enzymes \& then the degradation by products interfere with the normal process of vesicle fusion to the plasma membrane. $\downarrow$

Inhibition of the exocytosis of acetylcholine, leading to neuromuscular blocking effect.
Though very large doses can result in complete paralysis, therapeutic doses allow partial activity.

\section{Therapeutic uses}

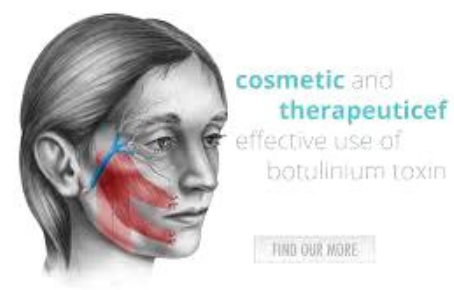

Botulinum toxoid can be used in variety of treatments from cosmetic uses in the removal of lines and wrinkles and enhancing the lost volume of the face using dermal fillers to its use in treatment of tremors and also pain management. The table below summarizes some of its uses. ${ }^{9}$

\begin{tabular}{|c|c|}
\hline Diseases & Subtypes \\
\hline $\begin{array}{l}\text { Non-dystonic disorders of } \\
\text { involuntary muscle activity }\end{array}$ & $\begin{array}{ll}\text { 1. } & \text { Hemifacial spasm } \\
\text { 2. } & \text { Tremor } \\
\text { 3. } & \text { Tics } \\
\text { 4. } & \text { Myokymia and synkinesis } \\
\text { 5. } & \text { Myoclonus }\end{array}$ \\
\hline $\begin{array}{l}\text { Spasticity } \\
\text { Velocity-dependent increase in } \\
\text { muscle tone }\end{array}$ & 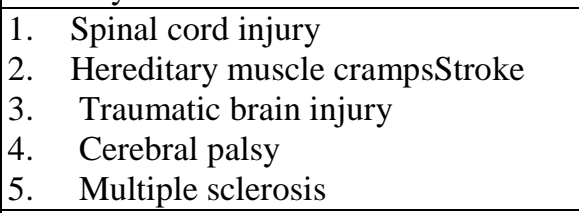 \\
\hline $\begin{array}{l}\text { Focal dystonia } \\
\text { Involuntary, sustained or } \\
\text { spasmodic patterned muscle } \\
\text { activity }\end{array}$ & $\begin{array}{ll}\text { 1. } & \text { Cervical dystonia } \\
\text { 2. } & \text { Blepharospasm } \\
\text { 3. } & \text { Laryngeal dystonia } \\
\text { 4. } & \text { Limb dystonia } \\
\text { 5. } & \text { Oromandibular dystonia } \\
\text { 6. } & \text { Orolingual dystonia } \\
\text { 7. } & \text { Truncal dystonia }\end{array}$ \\
\hline $\begin{array}{l}\text { Strabismus and nystagmus } \\
\text { Disorder of conjugate eye } \\
\text { movement and rapid } \\
\text { involuntary rhythmic eye } \\
\text { movement Disorders of } \\
\text { localized muscle spasm and } \\
\text { pain }\end{array}$ & $\begin{array}{l}\text { 1. Chronic back pain } \\
\text { 2. Myofascial pain syndrome } \\
\text { 3. Temporomandibular joint disorders } \\
\text { associated with increased muscle } \\
\text { activity. } \\
\text { 4. Tension headache } \\
\text { 5. Migraine headache }\end{array}$ \\
\hline $\begin{array}{l}\text { Smooth muscle hyperactive } \\
\text { disorders }\end{array}$ & $\begin{array}{l}\text { 1. Detrusor sphincter dyssynergia } \\
\text { 2. Achalasia cardia } \\
\text { 3. Chronic anal fissures }\end{array}$ \\
\hline Sweating disorders & 1. Frey syndrome \\
\hline
\end{tabular}




\begin{tabular}{|l|ll|}
\hline & 2. & Axillary and palmar hyperhidrosis \\
\hline Cosmetic uses & 1. & Hyperkinetic facial lines \\
& 2. & Hypertrophic platysma muscle bands \\
\hline
\end{tabular}

\section{Botox and its use in dentistry}

Today in the age of minimal invasive dentistry, botox being one such minimaly invasive option for a number of dental conditions is expanding its zones of useage and thus popularity.

Dental diseases are a result of two main factors, the microbial colonization in the oral cavity and the overactive orofacial musculature. The hyperactive orofacial musculature exerts excessive biting forces and dental trauma which results in varied forms of damage to the teeth and periodontium. Some of those conditions in which Botulinum Toxoid can be found useful are: bruxism, TMJ disorders, asymmetrical smiles, oromandibular disorders, excessive gingival display,black triangles, dental implants and maxillofacial fractures, Temporomandibular dislocation, Massetric hypertrophy, Mandibular spasm, Sialorrhea, Pathologic clenching, Angular chelitis, Decreased facial height, q3Orthodontic relapse

1. Myofunctional pain

2. Caner and palliative care

3. Denture wearers

These muscle generated damages can be managed both by non-surgical and surgical methods, but are invasive, irreversible and expensive for mostly all patients.

Hence, the options available for preventive treatment of muscle generated dental diseases which requires effective and safe agents that have minimal side effects which are well tolerated for long term use and will eliminate or reduce the need to use other irreversible treatment modalities. The injections of Botulinum toxin or botox have shown promising results in managing the hyperactive orofacial musculature.

Temporomandibular disorders: Temporomandibular joint disorders (TMD) is a term given by Bell. ${ }^{10}$ It signifies not only disorders of the temporomandibular joint (TMJ) but also includes a spectrum of disturbances associated with the function of masticatory system, which are poorly understood and thus mixed with other chronic pain disorders. These disturbances had been previously termed as TMJ dysfunction syndrome, functional TMJ disturbances, myofascial pain dysfunction syndrome, and temporomandibular pain dysfunction syndrome.

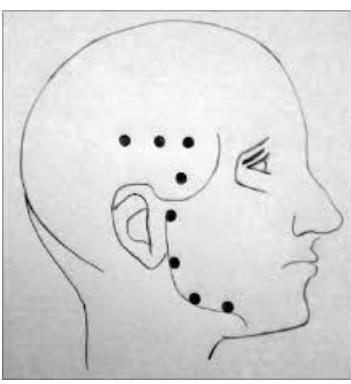

TMDs may be

1. Myofascial (related to muscles) or

2. Arthrogenic (related to TMJ), but majority of TMDs include a myogenic component and muscular spasticity in relation to bruxism, external stressors, OMD, and psychomotor behaviors. ${ }^{33}$ Conventional treatment approaches for TMDs include physiotherapy and exercise,anti-inflammatory and analgesic drugs, muscle relaxants, appliances (like stabilization splints), or a combination of these modalities. Surgery is sometimes indicated but is an expensive and invasive treatment option. BTA has been found to be effective in resolving pain and tenderness in TMDs. ${ }^{11,12}$ There are a diverse group of TMDs and those that are likely to be benefited by injection of BT includes the following: ${ }^{13}$

a. Bruxism and clenching

b. OMDs

c. Myofascial Pain

d. Trismus

e. Hypermobility

f. Masseter and temporalis hypertrophy

g. Headaches.

Although no definite management protocol has been proposed, various case reports have recorded significantly decreased pain with improved function and mouth opening. With doses ranging from 25 to 150 $\mathrm{U}$ of Botox ${ }^{\circledR}$ injected intramuscularly into the temporalis and the masseter muscles. ${ }^{14}$ Injecting BTA into lateral pterygoid muscle has been found to be effective in the treatment of recurrent mandibular dislocation. ${ }^{15}$

Bruxism: Bruxism is the severe clenching or grinding of teeth and is often associated with generalized attrition, muscular pain with TMJ symptoms and headaches. BTA has been used successfully in cases of bruxism. ${ }^{16}$ Injection of BTA bilaterally into masseter muscles (dose range of 25-100 MU per side) has been reported to significantly reduce the severity of symptoms for 6-78 weeks. In comparison to the oral splint, Botox is equally effective on bruxism. Injections at a dose of $<100 \mathrm{U}$ are safe for otherwise healthy patients. ${ }^{17}$ Use of BTA in nocturnal bruxism has 
increased recently and been found of help.A single injection has shown to be effective for at least a month. ${ }^{18}$

Mandibular Spasm: When the mandibles closing muscles remain semi contracted or in a state of spasm, it limits the mouth opening. This type of muscular spasm puts limitations on maintaining the basic oral hygiene which is necessary to prevent oral diseases. ${ }^{19}$ Among other issues are difficulty in eating, restrictions on dental treatment and diminished oral utility (impairement of a broad spectrum of oral functions). Botox therapy to the masticatory musculature diminishes the effects of hyperfunctional or spastic muscles. ${ }^{20}$

Oromandibular Dystonia: (OMD) is a movement disorder characterized by muscle contractions and involuntary spasms. Manifested as distorted oral position and function resulting in a difficulty to speak, swallow, and eat. Though it is a neurologic disorder, it is included under TMD because of its masticatory apparatus involvement. Most of the reports on OMD have been open-label studies, but all of them have shown improvements with botulinum toxin injections..$^{21-25}$ Botulinum toxin type A was injected into the masseter and/or the submental complex and an improvement in function was noted.

\section{Gummy smile}
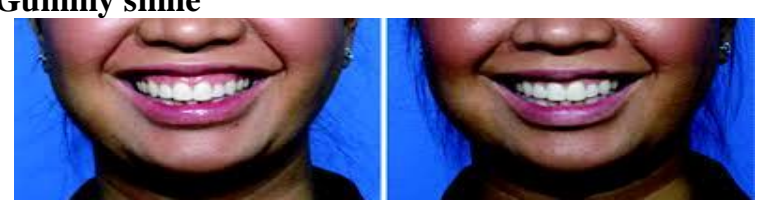

The display of excessive gingival tissue in the maxilla on smiling is a "gummy smile". It is both of an oral hygiene and cosmetic issue with no simple remedy. Excessive gum exposure is attributable to overcontraction of the upper lip muscles, particularly the levator labii Superioris alaeque nasi. Although several surgical techniques have been known in the literature for the correction of hyperfunctional upper lip elevator muscles, such as the Rubinstein and Kostianovsky, ${ }^{26}$ Miskinyar, ${ }^{27}$ and Rees and LaTrenta ${ }^{28}$ techniques. These are not routinely used to treat gummy smile. ${ }^{29}$ In general, the most common surgical intervention currently used are the LeFort I maxillary osteotomies with impaction for skeletal vertical maxillary excess, and gingivectomies for delayed passive dental eruption with excessive gingival display. ${ }^{29,30}$ Botulinum toxin should be injected in small amounts, carefully titrated doses to limit muscular over-contraction of upper lip, thus reducing exposure of the upper gums while smiling. Hwang et al., at Yonsei University College of dentistry, Seoul, Korea has proposed an injection point for botox and named it as Yonsei point. ${ }^{31}$ Yonsei point is a point located at the centre of triangle formed by levator labii superioris, levator labii superioris alaeque nasi and zygomaticus minor. A dose of $3 \mathrm{U}$ is recommended at each injection site.

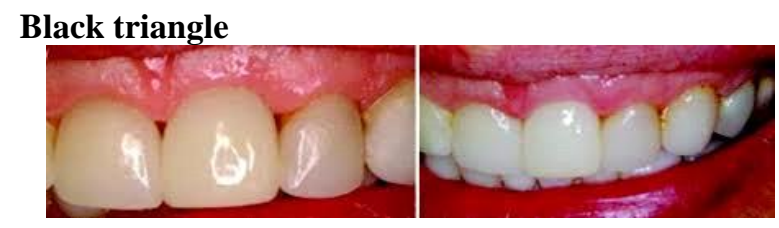

Black triangles being one of the most challenging esthetic concerns post placement of crowns, bridges and especially implants or even after periodontal surgery. Injecting BT into these areas plumps up the papilla and is a very minimally invasive way to create proper and more pleasing gingival contours. ${ }^{50}$

Drooping of corners of mouth: Hyperactivity of depressor anguli oris often leads to drooping of the corners of the mouth. Injection of BTA shows to have positive results in such cases. ${ }^{32}$ The site of injection is on the trajectory of nasolabial fold to the jaw line. Injections are to be given bilaterally in doses of about 2-5 U.

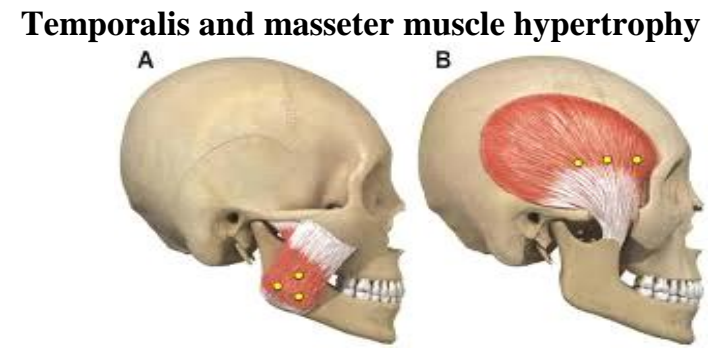

Hypertrophy of temporalis and masseter muscles is associated mostly with clenching or other parafunctional movements. The results of BT use in such cases with masseter and temporalis muscle hypertrophy are seen to be safe and effective in the treatment of chronic facial pain associated with masticatory hyperactivity. ${ }^{33}$ Injection sites are to be identified by palpation during clenching, dose of $12 \mathrm{U}$ of BTA percutaneous in the thickest part of the muscle has to be given.

Myofunctional Pain: Botox has proved to be effective and safe for the management of pain in maxillofacial region, especially in that of cervical dystonia and chronic facial pain associated with masticatory hyperactivity. BTA has been found to be effective in cases of trigeminal neuralgia without any major side effects. ${ }^{34} \mathrm{BT}$ is thus becoming a minimally invasive method of choice in treating trigeminal neuralgia over other invasive treatment modalities.

Facial nerve palsy: BTA injection treatment was effective in reducing facial sinking, thus improving the facial expressions symmetry both at rest and during voluntary movements ${ }^{35}$ One of the complications of facial nerve palsy is hyper lacrimation (i.e. crocodile tears) associated with salivation due to the aberrant 
connection between secretomotor fibers of salivary gland to the lacrimal gland. The Injection of BT into lacrimal gland has shown success in managing this condition.

Dental Implants and Maxillofacial Trauma: In Implantology BT has been postulated to be therapeutically beneficial. As it allows unimpeded osseointegration of implants. Stress due to any excessive functional force or any parafunctional habit may lead to failure of the implant. Thus, injecting BTA relaxes the masticatory muscles, leading to unimpeded osseointegration by sparing the implants. ${ }^{36}$ However, the use of BT in implantology demands further research. ${ }^{37}$

Maxillofacial trauma: Use of Botox in treating the injuries affecting the bones in the maxillofacial region including maxilla, zygoma, nasal bone, orbital bone, mandible has shown amusing results.Study done by Kayikçioglu et al. showed that temporary paralysis of masseter muscles allowed for fewer mini plates/microplates in the treatment of zygomatic fractures and thus the use of botox. ${ }^{38}$ Use of BTA in the management of condylar fracture has been strongly recommended under various reports. ${ }^{39}$ Higher doses of BTA may be used as a pharmaceutical splint during management of fractured facial bone. BTA injections in the anterior belly of digastric have been used in the correction of post traumatic anterior open bite successfully. ${ }^{40}$ BTA has also been proposed in the management of ranula as a minimally invasive adjunct therapy. ${ }^{41}$

Orthodontic Relapse Prevention: Relapse following an orthodontic correction may occur in patients with a strong muscular activity like that of the mentalis muscle. Thus during treatment to reduce the intensity of the muscle contractions. Muscles can be gradually trained post treatment to a more physiologic movement with the use of BTA. ${ }^{8}$

For Denture wearers: Muscles of the jaw aadapt themselves to the changing functional demands by changing their properties in terms of size and cross sectional area. ${ }^{42}$ Botox can thus be used in patients who are strugling to adjust to a new set of dentures because of thir irregulaar and uncoordinated muscle activities specially for those who have remained edentulous for long and also for those who have decreased vertical dimension by relaxing the muscles.

Sialorrhea and salivary secretory disorders: Sialorrhea or excessive salivation/drooling is a common problem caused by poor oral and facial muscle control. Treatment options can range from a conservative medical line to a more aggressive surgical approach. Effects of BTA on salivary glands has been studied. The injection of BTA into the parotid and submandibular glands is effective to control drooling. ${ }^{43}$ Botox is administered in a dose ranging from $30-70 \mathrm{U}$ into parotid gland and a significant reduction in salivary flow is observed within 4 weeks. The effect fades in about 3 months and then repeat injections are required. BTA injections has also been shown to be effective in managing gustatory sweating as in Frey's syndrome. ${ }^{44}$

Cancer and palliative care: The application of BTA can improve movement disorders following reconstructive surgery in patients with cancers of the parotid gland. Also as an antispasticity agent in palliative care for severe pain. ${ }^{45}$ The application of BTA is a minimally invasive treatment protocol in various functional disorders. So, improving the quality of life in patients with head and neck cancers of different etiologies with minimal side effects.

\section{Diagnostic Application}

In patients with chronic intermittent toothaches, BTA is used to verify the origin of this pain if it is muscular or pulpal. Thus, BTA in such cases can be used prophylactically as well as diagnostically. ${ }^{15}$

\section{Preperation of the injection site}

1. Alcohol wipes and dry sterile gauze sponges can be used to clean the skin.

2. Aspiration before injection is advised.

3. The syringe preffered is a calibrated $1.0-\mathrm{ml}$ tuberculin syringe, and the needle is usually is between gauge 26 to 30 .

4. Dosage is established by the diagnosis and the use of the toxin, size of the muscle, and medical conditions or other medications.

5. The number of injection sites usually is determined by the size of the muscle. Theoretically, it is more appropriate to inject more sites with smaller doses, and thus using more injection sites facilitates a wider distribution of the toxoid to the nerve terminals. But, too many injection sites may cause pain at the site later.

6. Proper targeting of the muscles is a crucial factor in achieving efficacy and reducing adverse effects from Botox injections. (The therapeutic effects of BTA first appear in 1 to 3 days, peak in 1 to 4 weeks, and decline after 3 to 4 months). ${ }^{46}$

\section{General guidelines}

1. Preparation has to be used within $4 \mathrm{~h}$

2. The area of the injection has to be covered with a topical anesthetic cream (or anesthetized using other modalities)

3. Starting with a lower dose initially.

4. Muscles should not be completely paralyzed.

5. Males mostly require higher doses due to their larger muscle masses.

\section{Side effects of botox therapy}

1. The injected muscles may become sore for a few days.

2. BT injections into muscles can cause temporary partial weakening of those muscles . 
3. When Botox is used for a long time, it may cause atrophy of the muscles it has been continuously been injected into. This atrophy is reversible only on discontinuation of the therapy.

4. There have been reports of temporary side effects such as flu-like symptoms, palpitations, tingling sensations, or nausea. These are rare and usually go within 1-2 days.

\section{Contraindications}

1. In any known hypersensitivity reaction to any of the botulinum preparations.

2. Allergy to any of the constituents of Botulinum toxoid serotypes. ${ }^{15}$

3. During Pregnancy and lactation ${ }^{47}$

4. Presence of active infection at the proposed injection site ${ }^{48}$

5. Patients receiving treatment with aminoglycosides, anticholinergic drugs or other agents interfering with neuromuscular transmission or muscle relaxants should be observed closely because the effect of Botox may be potentiated.

6. Patients suffering from peripheral motor neuropathic diseases, sclerosis, or any neuromuscular junction disorders like myasthenia gravis are at increased risk for clinically significant adverse reactions and thus need to be monitored closely.

7. In Psychologically unstable patients. ${ }^{15}$

8. As such there are no absolute contraindications but a few relative contraindications like pregnancy, lactation, neuromuscular diseases (myasthenia gravis, Eton-Lambert syndrome), motor-neuron diseases, concurrent usage of amino glycosides and sensitivity to toxins as mentioned above. The potential adverse effects of Botulinum toxin in oromandibular disorders include facial nerve palsy, pain at the injection site, flu-like symptoms, nontargeted muscle weakness, dysphagia, and hematoma. These effects of BT therapy are transient mostly and are known to resolve within a few days to couple of weeks.

\section{Status of botox in India}

Dr Madhuri Behari, the head of neurology at All India Institute of Medical Sciences (AIIMS) Delhi is a pioneer in botox therapy in India. It was Dr.Behari's work that made the Ethics Committee of AIIMS to approve botox as a treatment modality for blepharospasms. ${ }^{49}$ Injection costs range stars from Rs. 5000 per injection in India. ${ }^{51}$

The Indian Academy of Facial Esthetics (IAOFE) in association with the American Academy of Facial Esthetics (AAFE) is a professional and multidisciplinary organization, whose primary mission is teaching the best non-surgical and non-invasive facial esthetic techniques such as dermal filler training courses and Botulinum Toxin (Botox) Training Courses for dentists and other physicians. The Indian Academy of Facial Esthetics continues to develop successful proven techniques and trains dentists to integrate these procedures into their dental therapeutic and dental esthetic treatment plans. ${ }^{52}$

\section{Conclusion}

Botulinum toxin therapy is a promising and exciting novel addition to a dentist's arsenal. For varied uses like in the treatment of various orofacial and cosmetic corrections. BT provides a treatment that is conservative, reversible, quick and painless in comparison to the other surgical alternatives. They are on the run to become an integral part of everyday dental practice including restorative, aesthetic, periodontic, orthodontic and prosthodontic implications. They provide the patients with most predictable, minimally invasive, aesthetic and therapeutic outcomes available for many everyday clinical situations. But there are still many dental conditions which require FDA approval to be treated by botulinum toxoid. It is evident that Botox offers a wide range of valuable solutions for a dentist and will surely take dentistry a level ahead in the field of progress.

\section{References}

1. .Peck S, Peck L, Kataja M. Some vertical linear measurement of lip position. Am J Orthod Dentofac Orthop 1992;101:515-24.

2. Kukreja R, Singh B. "Botulinum neurotoxins: structure and mechanism of action". Microbial toxins: current research and future trends. 2009, Caister Academic Press.

3. Clostridium Botulinum- Public health agency of Canada. Phac-aspc.gc.ca (201104-19). Retrieved on 2012-05-06

4. Snipe, P. Tessme, Sommer. Studies on botulinus toxin: 3 . Acid precipitation of botulinus toxin. J Infectious Dis 43(2):152-60.

5. Dastoor SF, Misch CE, Wang HL. Botulinum toxin (Botox) to enhance facial macroesthetics: A literature review. J Oral Implantol 2007;33(3):164-71.

6. http://www.accessdata.fda.gov/scripts/cder/ drugsatfda/index.cfm?fuseaction=Search.Label_ ApprovalHistory\#apphist.

7. On February 8, 2008, the FDA did publish a notice that Botox Cosmetic (botulinum toxin type A) and Myobloc (botulinum toxin type B) had been linked in some cases to adverse reactions, including respiratory failure and death, following treatment of a variety of conditions using a wide range of doses. The adverse reactions appeared to be related to the spread of the toxin to areas distant from the site of injection, mimicking symptoms of botulism. http://www.fda.gov/

NewsEvents/Newsroom/PressAnnouncements/2008/ ucm116857.htm

8. PranavNayyar, Pravin

Kumar, PallaviVashishtNayyar, Anshdeep Singh. BOTOX: Broadening the Horizon of Dentistry. J Clin Diagn Res 2014;8(12):ZE25-9.

9. Sunny

Manchanda2, Suman Thotapalli3, Sunil Babu Kotha4; Botox Therapy in Dentistry: A Review Aftab Azam1; $J$ Int Oral Health 2015;7(Suppl 2):103-5. 
10. Bell WE. Clinical Management of Temporomandibular Disorders. Chicago: Year Book Medical Publishers; 1982.

11. Freund B, Schwartz M, Symington JM. The use of botulinum toxin for the treatment of temporomandibular disorders: Preliminary findings. J Oral Maxillofac Surg 1999;57:916-20

12. Lee KM, Chow J, Hui E, Li W. Botulinum toxin type A injection for the management of myofascial temporomandibular pain disorder. Asian J Oral Maxillofac Surg 2005;17:100-3.

13. Schwartz M, Freund B. Treatment of temporomandibular disorders with botulinum toxin. Clin J Pain 2002;18 6 Suppl:S198-203.

14. Song PC, Schwartz J, Blitzer A. The emerging role of botulinum toxin in the treatment of temporomandibular disorders. Oral Dis 2007;13:253-60.

15. Sanjeev Srivastava, Smriti Kharbanda1, U. S. Pal2, Vinit Shah3; Applications of botulinum toxin in dentistry: A comprehensive review; Downloaded free from http://www.njms.in

16. Tan EK, Jankovic J. Treating severe bruxism with botulinum toxin. J Am Dent Assoc 2000;131:211-6.

17. Long H, Liao Z, Wang Y, Liao L, Lai W. Efficacy of botulinum toxins on bruxism: An evidence-based review. Int Dent J 2012;62:1-5.

18. Shim YJ, Lee MK, Kato T, Park HU, Heo K, Kim ST. Effects of botulinum toxin on jaw motor events during sleep in sleep bruxism patients: A polysomnographic evaluation. J Clin Sleep Med 2014;10:291-8.

19. Erdal J, Werdelin L, Prytz S, et al. Experience with longterm botulinum toxin treatment of oromandibular dystonia, guided by quantitative EMG. Acta Neurologica Scandinavica 1996;94(6):210.

20. Cersosimo MG, Bertoti A, Roca CU, et al. Botulinum toxin in a case of hemimasticatory spasm with severe worsening during pregnancy. Clin Neuropharmacol 2004;27(1):6-8.

21. Brin MF, Fahn S, Moskowitz C, et al. Localized injections of botulinum toxin for the treatment of focal dystonia and hemifacial spasm. Mov Disord 1987;2(4): 237-54.

22. 22.Hermanowicz N, Truong DD. Treatment of oromandibular dystonia with botulinum toxin. Laryngoscope 1991;101(11):1216-18.

23. Jankovic J, Orman J. Botulinum toxin for cranial-cervical dystonia: a double-blind, placebo-controlled study. Neurol 1987;27:616-23.

24. Laskawi R, Rohrbach S. Oromandibular dystonia Clinical forms, diagnosis and examples of therapy with botulinum toxin. Laryngorhinootologie 2001;80(12):70813.

25. Tan EK, Jankovic J. Botulinum toxin A in patients with oromandibular dystonia: Long-term follow-up. Neurology 1999;53(9):2102-07.

26. laugh: original technique. Prensa Med Argent. 1973;60:952.

27. Miskinyar SA. A new method for correcting a gummy smile. Plast Reconstr Surg 1983;72:397-400.

28. Rees T, LaTrenta G. The long face syndrome and rhinoplasty. Persp Plast Surg 1989;3:116.

29. Polo M. Botulinum toxin type A in the treatment of excessive gingival display. Am J Orthod Dentofacial Orthop 2005;127(2):214-8.

30. Amin V, Amin V, Swathi, Jabir A, Shetty P. Enhancing the smile with Botox-case [22] report. Global J Med Res 2013;13(2):14-8.
31. Hwang, et al. Surface anatomy of the lip elevator muscles for the treatment of [23] gummy smile using botulinum toxin. Angle Orthod. 2009;79(1):70-7.

32. Choi YJ, Kim JS, Gil YC, Phetudom T, Kim HJ, Tansatit $\mathrm{T}$, et al. Anatomical considerations regarding the location and boundary of the depressor anguli oris muscle with reference to botulinum toxin injection. Plast Reconstr Surg 2014;134:917-21.

33. Moore AP, Wood GD. The medical management of masseteric hypertrophy with botulinum toxin type A. $\mathrm{Br} \mathrm{J}$ Oral Maxillofac Surg 1994;32:26-8.

34. Bohluli B, Motamedi MH, Bagheri SC, Bayat M, Lassemi E, Navi F, et al. Use of botulinum toxin A for drug-refractory trigeminal neuralgia: Preliminary report. Oral Surg Oral Med Oral Pathol Oral Radiol Endod 2011;111:47-50.

35. Montoya FJ, Riddell CE, Caesar R, Hague S. Treatment of gustatory hyperlacrimation (crocodile tears) with injection of botulinum toxin into the lacrimal gland. Eye (Lond) 2002;16:705-9.

36. Ihde S. Prophylactic use of botulinum toxin in dental implantology. CMF Implement Dir 2007;1:29-34.

37. Ihde SK, Konstantinovic VS. The therapeutic use of botulinum toxin in cervical and maxillofacial conditions: An evidence-based review. Oral Surg Oral Med Oral Pathol Oral Radiol Endod 2007;104:e1-11.

38. Kayikçioglu A, Erk Y, Mavili E, Vargel I, Ozgür F. Botulinum toxin in the treatment of zygomatic fractures. Plast Reconstr Surg 2003;111:341-6.

39. Akbay E, Cevik C, Damlar I, Altan A. Treatment of displaced mandibular condylar fracture with botulinum toxin A. Auris Nasus Larynx 2014;41:219-21.

40. Seok H, Park YT, Kim SG, Park YW. Correction of posttraumatic anterior open bite by injection of botulinum toxin type A into the anterior belly of the digastric muscle: Case report. J Korean Assoc Oral Maxillofac Surg 2013;39:188-92.

41. Chow TL, Chan SW, Lam SH. Ranula successfully treated by botulinum toxin type A: Report of 3 cases. Oral Surg Oral Med Oral Pathol Oral Radiol Endod 2008;105:41-2.

42. Grünheid T, Langenbach GE, Korfage JA, Zentner A, van Eijden TM. The adaptive response of jaw muscles to varying functional demands. Eur J Orthod 2009;31:596612.

43. Benson J, Daugherty KK. Botulinum toxin A in the treatment of sialorrhea. Ann Pharmacother 2007;41:7985.

44. Beerens AJ, Snow GB. Botulinum toxin A in the treatment of patients with Frey syndrome. Br J Surg 2002;89:116-9.

45. Laskawi R, Ellies M. The role of botulinum toxin in the management of head and neck cancer patients. Curr Opin Otolaryngol Head Neck Surg 2007;15:112-6.

46. Mini Jain, Abhishek Bansal, Disha Agarwal, Monika Joshi1 ; Botox in Dentistry: The Healing Side of a Poison

47. Katz H. Botulinum toxins in dentistry - The new paradigm for masticatory muscle hypertonicity. Singapore Dent J 2005;27:7-12.

48. Hurkadle JK, Jatania A, Shanthraj R, Lakshmi B, Subbiah P, Linga S. Botox: Buy me beauty. J Orofac Res 2012;2:160-4.

49. Chandra S, Devi MP, Ravindra SV, Singh D, Kumar S. Botoxonomics : A palliative prick. Int J Sci Stud 2014; 2(6):108-111.

50. The new science of Botox. Available in Indiatoday.intoday.in/story/botox- treatment-in-india-is- 
becoming-popular-for-all pains/1/155750.html [Last accessed on 26/09/2015].

51. Now, shell out Rs.5000 for instant youth. Available in https://in.lifestyle.yahoo.com/now--shell-out-rs-5000-forinstant-youth-.html [Last accessed on 26/09/2015].

52. The Botulinum Toxin Training Course and Dermal Filler Training Course for Dentists and Physicians. Available in www.iaofe.com [Last accessed on 26/09/2015]. 